\title{
ANALISIS FAKTOR YANG MEMPENGARUHI PENDAPATAN MASYARAKAT PASCA TSUNAMI
}

\author{
ANALYSIS OF FACTORS INFLUENCING PEOPLES'S INCOME \\ AFTER TSUNAMI
}

Fadli $^{1)}$

\begin{abstract}
Analysis of factors influencing people's income after tsunami. Income is the main factor in improving the walfare of society. Post-tsunami community life certainly very difficult, all sources of income and their property destroyed by the brunt of the tsunami waves. Human capital, physical capital and economic capital and social capital is also a key factor in increasing rural incomes post-tsunami. This study aims to analyze the factors that influence people's income after the tsunami. Data were analyzed by regression analysis. The research show that social capital is a factor which significantly affect the increase in income after the tsunami.
\end{abstract}

\section{Keywords: Revenue, Trusty, Collaboration, Network, Collective Action, and Relief Fund}

\section{PENDAHULUAN}

Prioritas program rencana rehabilitasi dan rekonstruksi pasca bencana tertuang dalam Buku Induk Rencana Rekonstruksi dan Rehabilitasi Aceh dan Nias (2005). Pembangunan pasca tsunami di prioritaskan pada pembangunan kembali berbagai sektor kehidupan masyarakat yang telah hancur. Kebijakan dan strategi dalam proses rehabilitasi pasca bencana didasarkan pada upaya mengentaskan permasalahan yang ditimbulkan oleh tsunami.

Pembangunan kembali pasca tsunami bertujuan untuk meningkatkan kesejahteraan masyarakat secara adil dan merata untuk setiap wilayah yang mengalami kerusakan melalui pemenuhan kebutuhan hidupnya yang paling mendasar. Peningkatan kesejahteraan dapat dilakukan dengan cara peningkatan pendapatan. Adanya pendapatan pasca tsunami membantu mereka untuk memenuhi seluruh kebutuhan dirinya dan keluarganya. Pendapatan akan ada atau didapat jika didukung oleh faktor yang mempengaruhinya. Faktor yang mempengaruhi pendapatan diantaranya yaitu tersedianya sumberdaya alam, modal, manusia dan sumber lainnya. Bawaan sumberdaya (resource endowment) yaitu sumberdaya alam (natural resources), sumberdaya manusia (human resources), sumberdaya buatan (man-made resources) atau infrastruktur dan sumberdaya sosial (social resources) menjadi sangat penting bagi tercapai tujuan peningkatan kesejahteraan. Akan tetapi, pasca tsunami masyarakat hampir tidak lagi memiliki bawaan sumberdaya yang dimaksud. Namun demikian, stok modal sosial, pendidikan, jumlah anggota keluarga yang masih tinggal, pekerjaan dan bantuan pihak luar yang masih dimiliki dapat digunakan sebagai modal dalam proses peningkatan pendapatannya.

Modal sosial yang masih dimiliki oleh masyarakat berpengaruh terhadap percepatan pembangunan desanya baik pembangunan infrastruktur dan perumahan maupun pembangunan ekonominya. Modal social yang dimaksud yaitu aksi kolektif, kepercayaan dan kerjasama. Aksi kolektif seperti melakukan proses perencanaan pembangunan desa secara partisipatif pasca tsunami yang salah satu hasilnya adalah membentuk kelompok-kelompok usaha yang sesuai dengan bidang dan keahlian masing-masing masyarakat. Dengan telah terbentuknya kelompok-kelompok tersebut menyebabkan banyak pihak yang menawarkan bantuannya untuk peningkatan pendapatan mereka. Kerjasama tersebut terjadi karena antar sesama masyarakat saling percaya mempercayai. Modal kepercayaan yang ada menjadi modal untuk menarik minat pihak-pihak yang mau memberi bantuan.

Modal kepercayaan dan kerjasama juga berimplikasi pada adanya modal sosial, karena kepercayaan adalah produk yang sangat penting dari norma-norma sosial kooperatif yang memunculkan modal sosial. Jika masyarakat bisa diandalkan untuk tetap menjaga komitmen, norma-norma saling menolong yang terhormat dan menghindari perilaku oportunistik, maka berbagai kelompok akan terbentuk secara lebih cepat, dan kelompok yang terbentuk itu akan mampu mencapai tujuan-tujuan bersama secara lebih efisien (Fukuyama 1995). 
Dengan demikian modal sosial dapat berperan untuk mendorong percepatan pembangunan desa pasca tsunami.

Faktor lain yang masih ada sebagai modal untuk peningkatan pendapatan pasca tsunami yaitu pendidikan, anggota keluarga, pekerjaan dan bantuan pihak luar. Pendidikan seseorang yang tinggi tentu akan mudah memperoleh pekerjaan. Pasca tsunami banyak lembaga donor yang berkantor di Aceh dan menyediakan pekerjaan bagi masyarakat. Selain itu anggota keluarga juga berkontribusi di dalam pemenuhan kebutuhan keluarganya. Sama halnya dengan pendidkan dan jumlah keluarga yang masih dimiliki, keterlibatan pihak luar juga menjadi penentu masyarakat di dalam mendapatkan penghasilan. Keterlibatan lembaga swadaya baik yang berasal dari dalam negeri maupun yang dari luar negeri membantu masyarakat untuk memperoleh bantuan dalam bentuk penyediaan modal usaha maupun bantuan langsung tunai. Namun demikian sejauhmana faktorfaktor tersebut mempengaruhi atau berpengaruh terhadap pemulihan pendapatan masyarakat sebagai upaya pengentasan masalah ekonomi yang ditimbulkan oleh tsunami perlu dilakukan sebuah penelitian.

Penelitian ini bertujuan untuk menjawab beberapa permasalahan yang terkait dengan pendapatan masyarakat pasca tsunami dan mendapatkan informasi atau pengetahuan mengenai hubungan/konstribusi modal sosial masyarakat, pendidikan, jumlah anggota keluarga, pekerjaan dan bantuan pihak luar dengan pendapatan masyarakat pasca tsunami.

\section{METODE PENELITIAN}

\section{Lokasi dan Sampel}

Penelitian dilaksanakan di Kabupaten Aceh Besar, yaitu di Desa Beurandeh Kecamatan Mesjid Raya, Desa Kajhu Kecamatan Baitussalam dan Desa Lamkrut Kecamatan Lhoknga, yang ditentukan secara sengaja (purposive). Sampel penelitian adalah rumah tangga yang ditentukan secara eksidental yaitu rumah tangga yang dipilih adalah rumah tangga mana saja yang dijumpai dan bersedia diminta informasinya sesuai dengan data yang dibutuhkan pada saat pengambilan data (Mantra 2004). Jumlah sampel yang diambil yaitu 61 rumah tangga, masingmasing 21 rumah tangga di Desa Kajhu, 20 rumah tangga di Desa Lamkrut dan 20 Rumah tangga di Desa Beurandeh.

\section{Jenis dan Sumber Data}

Jenis Data yang dikumpulkan meliputi Data Primer dan Data Sekunder. Data sekunder dikumpulkan dari lembaga/instansi yang berkaitan dengan penelitian ini. Sedangkan data primer dikumpulkan melalui wawancara terstruktur dengan menggunakan daftar kuesioner dengan kepala dan anggota rumah tangga. Selain itu juga melalui wawancara dengan pemimpin desa, tokoh masyarakat dan kelompok-kelompok masyarakat yang sedang berkumpul di suatu tempat.

\section{Metode Analisis Data}

Faktor yang berpengaruh terhadap pendapatan masyarakat pasca tsunami dianalisis dengan menggunakan regresi linier berganda. Bentuk persamaannya adalah sebagai berikut:

$$
Y=\beta_{0}+\beta_{1} M S+\beta_{2} U+\beta_{3} A K+\beta_{4} d_{-} P d K+\beta_{5} d_{-} P K+\beta_{6} N G O+\varepsilon
$$

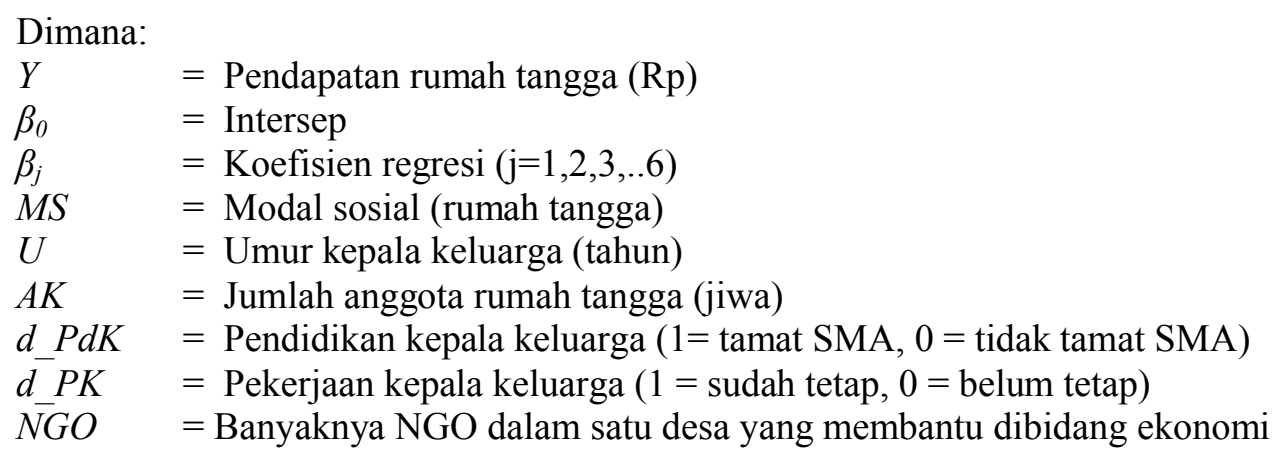




\section{HASIL PENELITIAN}

Pendapatan merupakan salah satu indikator kesejahteraan masyarakat. Semakin tinggi pendapatan, tingkat kesejahteraannya juga semakin tinggi. Pendapatan keluarga secara umum bisa dipengaruhi oleh tingkat pendidikan kepala keluarga, pekerjaan kepala keluarga, umur kepala keluarga, jumlah anggota rumah tangga, aset yang dimiliki rumah tangga dan lain sebagainnya.

Model yang digunakan untuk menganalisis faktor yang mempengaruhi pendapatan keluarga pasca tsunami adalah model regresi linier. Selain memasukkan variabel-variabel yang secara umum digunakan sebagai faktor yang mempengaruhi pendapatan keluarga yaitu pendidikan kepala keluarga, pekerjaan kepala keluarga, jumlah anggota keluarga, juga memasukkan faktor modal sosial masyarakat dan keterlibatan berbagai pihak sebagai penyedia bantuan dalam proses rehabilitasi dan rekonstruksi di NAD sebagai variabel bebasnya. Dengan memasukkan indeks modal sosial masyarakat, maka dapat dilihat seberapa besar modal sosial berpengaruh terhadap pemulihan pendapatan masyarakat pasca tsunami.

Hasil pengujian hipotesis terhadap model analisis regresi linier menunjukkan nilai probabilitas $<0,05$, maka model regresi linier tersebut layak digunakan untuk memprediksi faktor modal social, pendidikan kepala keluarga, jumlah anggota keluarga, pekerjaan kepala keluarga dan bantuan NGO berpengaruh terhadap pendapatan masyarakat pasca tsunami (Tabel 1). Hasil analisis menunjukkan bahwa pendapatan keluarga dipengaruhi secara nyata oleh indeks modal sosial masyarakat pada taraf nyata $95 \%$. Modal sosial memberikan pengaruh yang positif dan signifikan terhadap pendapatan keluarga pasca tsunami. Modal sosial merupakan salah satu faktor yang dapat memudahkan masayarakat untuk memulihkan pendapatannya. Kerjasama dan saling percaya sebagai unsur modal sosial memberi peluang masyarakat untuk memperoleh keuntungan secara kolektif, seseorang pecaya kepada orang lain karena ada tujuannya yaitu untuk mendapat keuntungan (Lawang 2004).

Selain itu, tingkat pendidikan kepala keluarga juga berpengaruh terhadap pemulihan pendapatan masyarakat pasca tsunami walaupun tidak begitu signifikan. Tingkat pendidikan kepala keluarga minimal SMA memberi pengaruh yang positif kepada peningkatan pendapatannya. Hal tersebut merupakan hal yang logis, mengingat pendidikan kepala keluarga yang sudah tamat SMA akan memudahkan dalam melakukan berbagai kegiatan. Sedangkan variabel keterlibatan NGO (d NGO) memiliki tanda positif artinya bahwa jumlah NGO yang terlibat dapat meningkatkan pendapatan masyarakat. Sumber peningkatan pendapatan masyarakat yang berkaitan dengan jumlah NGO yang terlibat yaitu terutama pada pembangunan fisik seperti pembangunan rumah. Sedangkan pada bidang ekonomi, modal usaha yang disalurkan belum mendapatkan hasil mengingat waktunya yang belum begitu lama sehingga usaha masyarakat belum memberikan hasil sesuai yang diharapkan.

Tabel 1. Hasil Analisis Menggunakan Regresi Linier dengan Variabel Terikat Pendapatan Rumah Tangga

\begin{tabular}{lcc}
\multicolumn{1}{c}{ Indikator } & Koefisienregresi & P-Value \\
\hline Konstanta & -22.706 & 0.192 \\
Indeks Modal Sosial Masyarakat $(M S)$ & 32.721 & 0.011 \\
Umur Kepala Rumah Tangga $(U)$ & $9.780 \mathrm{E}-02$ & 0.711 \\
Pekerjaan Kepala Rumah Tangga $\left(d_{-} P K\right)$ & 9.169 & 0.098 \\
Pendidikan Kepala Rumah Tangga $\left(d_{-} P d K\right)$ & 10.267 & 0.060 \\
Jumlah Anggota Rumah Tangga $(A K)$ & -0.843 & 0.589 \\
Keterlibatan NGO $(N G O)$ & 1.870 & 0.170 \\
R Square & 0.260 & \\
Adjusted R Square & 0.178 & 0.010 \\
F Statistik & & \\
\hline
\end{tabular}


Keterkaitan pendapatan masyarakat desa pasca tsunami dan modal sosial yaitu modal sosial dapat memfasilitasi terjadinya proses perolehan pendapatan yang lebih cepat. Penggunaan modal sosial yang tepat akan meningkatkan akses setiap orang untuk memperoleh pengetahuan, pendidikan, kesehatan, kenyamanan, perumahan dan kesempatan kerja sehingga kehidupannya akan lebih sejahtera. Modal sosial memfasilitasi orang untuk bekerja secara bersama-sama (collective action) untuk mencapai tujuan bersama.

Modal sosial memang bukan satu-satunya faktor yang mempengaruhi tercapainya tingkat kesejahteraan rumah tangga dan pembangunan wilayah yang tinggi. Banyak faktor-faktor yang juga mempengaruhinya seperti ketersediaan sumberdaya alam fisik serta sumberdaya manusia. Penelitianpenelitian tentang modal sosial yang pernah dilakukan menunjukkan bahwa modal sosial dapat mempengaruhi tercapainya tingkat kesejahteraan masyarakat dan pembangunan wilayah yang tinggi, khususnya pembangunan ekonomi suatu wilayah (Kirwen dan pierce, 2002, Knowles, 2005, Narayan dan Pritchett, 1999, North, 1990 serta Putnam, 1993).

Kerjasama dan saling percaya antar sesama masyarakat maupun dengan lembaga di dalam dan di luar komunitas masyarakat merupakan unsur utama modal sosial. Sering melakukan kerjasama dan tingkat kepercayaan yang tinggi memberi peluang masyarakat untuk memperoleh keuntungan secara kolektif. Aktivitas bersama yang dihasilkan dari adanya interaksi sosial yang intensif dapat meningkatkan produktifitas ekonomi.

\section{KESIMPULAN}

Peningkatan pendapatan masyarakat desa pasca tsunami dipengaruhi oleh stok modal sosial. Semakin tinggi stok modal sosialnya, proses menghasilkan pendapatan semakin cepat. Modal sosial menjadi faktor penentu peningkatan pendapatan masyarakat desa pasca tsunami disamping faktor lain yaitu pekerjaan, pendidikan, umur kepala keluarga dan keterlibatan pihak NGO, modal sosial dapat mendorong masyarakat untuk melakukan kerjasama (collective action) untuk mencapai tujuan bersama yaitu membangun kembali desa mereka yang telah hancur akibat tsunami.

\section{DAFTAR PUSTAKA}

Fukuyama, F. (1995). Trust: the social virtues and the creation of prosperity. The Free Press. New York.

Kirwen, E. L., Pierce, L. I. (2002). Rebuilding trust and social capital in Maluku, Indonesia. Prepared for the USAID DG Partners Conference December 2002.

Knowles, S. (2005). The future of social capital in economics development research. A paper for WIDER Jubilee Conference. Helsinki.

Lawang, R. M. Z.(2004). Kapital sosial dalam perspektif sosiologik suatu pengantar. FISIP UI PRESS. Jakarta.

Mantra, I. B. (2004). Filsafat penelitian dan metode penelitian sosial. Pustaka Pelajar. Yogyakarta.

Narayan, D., Pritchett, L.(1999). Cent and sociability. Household income and social capital in rural Tanzania. Economic Development and Cultural Change 47 (8): 871-986.

North, D. C. (1990). Institutions, institutional change and economic performance. Cambridge University Press. Cambridge.

Putnam, R. D. (1993). Making democracy work: civic tradition in modern Italy. Princeton University Press. Princeton. New Jersey. 